\title{
Simulating residential demand response: Improving socio-technical assumptions in activity-based models of energy demand
}

\author{
Eoghan McKenna • Sarah Higginson • \\ Philipp Grunewald • Sarah J. Darby
}

Received: 22 November 2016/Accepted: 26 April 2017 / Published online: 10 May 2017

(C) The Author(s) 2017. This article is an open access publication

\begin{abstract}
Demand response is receiving increasing interest as a new form of flexibility within low-carbon power systems. Energy models are an important tool to assess the potential capability of demand side contributions. This paper critically reviews the assumptions in current models and introduces a new conceptual framework to better facilitate such an assessment. We propose three dimensions along which change could occur, namely technology, activities and service expectations. Using this framework, the socio-technical assumptions underpinning 'bottom-up' activity-based energy demand models are identified and a number of shortcomings are discussed. First, links between appliance usage and activities are not evidence-based. We propose new data collection approaches to address this gap. Second, aside from thermal comfort, service expectations, which can be an important source of flexibility, are underrepresented and their inclusion into demand models would improve their predicative power in this area. Finally, flexibility can be present over a range of time scales, from immediate responses, to longer term trends. Longitudinal time use data from participants in demand response schemes may be able to illuminate these. The
\end{abstract}

This submission builds on work presented at the Behave2016 conference in Coimbra, Portugal

E. McKenna $(\bowtie) \cdot$ S. Higginson · P. Grunewald •

S. J. Darby

Environmental Change Institute, School of Geography and the Environment, University of Oxford, South Parks Road,

Oxford OX1 3QY, UK

e-mail: eoghan.mckenna@ouce.ox.ac.uk recommendations of this paper seek to enhance the current state-of-the-art in activity-based models and to provide useful tools for the assessment of demand response.

Keywords Demand response · Bottom-up · Simulation · Energy $\cdot$ Demand $\cdot$ Domestic $\cdot$ Residential $\cdot$ Service expectation $\cdot$ Activity $\cdot$ Time use $\cdot$ Appliance $\cdot$ Electricity

\section{Introduction}

Demand response - time-shifting electricity demand, usually in response to a variable price signal - has numerous potential benefits within electricity systems (Aghaei \& Alizadeh, 2013; Albadi \& El-Saadany, 2008) and is recognised as having the potential to support the integration of renewable energy into power systems, alongside energy storage, interconnection, and flexible generation (Budischak et al., 2013; Delucchi \& Jacobson, 2011; Elliston, Diesendorf, \& MacGill, 2012; Rasmussen, Andresen, \& Greiner, 2012). Demand response is a subject that is receiving growing attention from the energy industry and research community and there are numerous studies describing its potential benefits (Boßmann \& Eser, 2016; Haider, See, \& Elmenreich, 2016; Siano, 2014; Torriti, Hassan, \& Leach, 2010). Of the increasingly rich literature on demand response, much is located in engineering and applied energy journals, and focussed on technical potential and on energy storage systems, aspects of 
demand response that arguably assume and require least human interaction.

It is, however, important to consider socio-technical questions about the extent to which people and organisations might be willing and able to engage in demand response (Darby \& McKenna, 2012). What demand response tariffs and technologies are acceptable to consumers (Fell, Shipworth, Huebner, \& Elwell, 2015), and what might be their likely uptake? What factors affect the flexibility of everyday practices (Powells, Bulkeley, Bell, \& Judson, 2014)? Should demand response technologies be designed around constraints of minimising inconvenience or discomfort? One of the challenges that results from this type of question is the difficulty of incorporating social science insights about demand response into the quantitative engineering models that are used to evaluate future low-carbon power system scenarios (Higginson, McKenna, Hargreaves, Chilvers, \& Thomson, 2015).

Energy models play a critical role in shaping energy policy and decision-making and as such it is important to assess their ability to account for demand response. The paper investigates in detail the assumptions underpinning 'bottom-up' activitybased demand models, as this particular class of energy systems model is particularly suitable for demand response studies. Given the interest and value in evaluating demand response within lowcarbon studies, and the fact that there appears to be an under-realised potential for activity-based models to contribute to this field (Good, Karangelos, Navarro-Espinosa, \& Mancarella, 2015a), the primary aim of this paper is to examine how activitybased demand models may be enhanced to provide more useful tools for the assessment of demand response. The primary contribution of this paper is therefore the identification of the socio-technical assumptions used in activity-based models of energy demand and their evaluation for the purposes of demand response simulation.

\section{Background}

Socio-technical implications of smart grids

In Blumsack \& Fernandez, 2012, Blumsack and Fernandez claimed that 'researchers and policymakers need better models to evaluate the performance of smart grid systems, and to tie performance back to deployment goals... (and that) The pace of development ... has been moving faster than our ability to understand the technical and social implications of such a complex system' (Blumsack \& Fernandez, 2012). This remains true. Indeed, our ability to understand the implications of smart grid development is impeded by this dominant framing of smart grids as technical in nature, rather than sociotechnical. This bias persists even in a domestic setting, as noted in analyses of the smart home literature (Wilson, Hargreaves, \& Hauxwell-Baldwin, 2015; GramHanssen \& Darby, 2016). Human participation in a smart grid is all too often portrayed as consent to adopt a packaged 'solution', the outcomes of which are modelled on designer expectations rather than empirical data. Yet this hardly fits with what we know about demand (and supply) in terms of energy services (Sovacool, 2011), or practices (Baborska-Narozny, Stevenson, \& Ziyad, 2016; Walker, 2014), or with what we know of the inherent variability of quantified energy demand, given that it is an outcome of diverse practices in diverse situations (Janda, 2014; Lutzenhiser \& Bender, 2008). Learning, adaptation and skills, too, tend to be left out of the picture, although these strongly influence the nature and patterns of demand and the potential for these to change over time (Darby, 2006; Glad, 2012). The socio-technical challenge of demand response can be viewed as part of the broader one concerning smart grids. As with smart grids, therefore, we adopt the approach that, while there is value in assessing the role of enabling technology, reframing these subjects in broader socio-technical terms opens up new perspectives that merit exploration.

When assessing the potential for residential demand response, there is a need to turn first of all to questions of how energy services are accessed and how activities are undertaken. This sort of inquiry indicates where, when and how electricity for a service or activity is most likely to be necessary. Seen from another perspective, it shows where, when and how flexibility might be incorporated into an energy system. The literature on thermal comfort and adaptive response is a powerful example of this, e.g. (Nicol \& Humphreys, 2002; Shove, Chappells, Lutzenhiser, \& Hackett, 2008). In this paper we adopt the framing of demand response in terms of activities, services, and technologies, with the aim of better understanding the socio-technical implications of demand response for modellers and policy. 
Activity-based demand models

'Bottom-up' models ${ }^{1}$ simulate the use of individual appliances and loads within a dwelling and aggregate them together to provide an estimate of the energy demand of the whole dwelling. Figure 1 shows the overall architecture of one such model, in this case the CREST Demand Model (McKenna \& Thomson, 2015).

A characteristic feature of such models is a core representation of the occupancy and activity patterns of individual residents within the dwelling (highlighted 'activities' in the figure - which is why they are also known as 'activity-based' models). These are then combined with appropriate control settings (which we identify as 'service expectations' in the figure) to determine stochastic usage events for the appliances and fixtures ('technologies' in the figure) that have appropriate usage statistics. Due to their representation of activities, the electricity-using technologies used during these activities, and their associated service expectations, activitybased models have an appropriate high-level architecture for exploring demand response from a sociotechnical perspective.

Activity-based models for demand response studies

Within the field of energy research, ${ }^{2}$ activity-based models were initially developed primarily to investigate the impact of low-carbon technologies on low-voltage distribution networks (Baetens et al., 2012; Widén \& Wäckelgård, 2010). The development of such models, therefore, has been shaped by the requirements needed to ensure models are fit for this purpose. For example, a primary requirement for low-voltage network studies is the need to account accurately for the diversity of demand, as this is of critical importance to the sizing of low-voltage lines and transformers, and therefore of concern to network planners. This requirement led to use of stochastic techniques to account for the (at least partially) random nature of domestic electricity demand (McKenna \& Thomson, 2016). It also led to

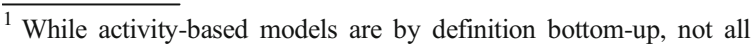
bottom-up models are activity-based. This paper focuses on activitybased models due to their potential relevance for demand response studies. A more general review of models for demand response, including both top-down and bottom-up models (though not activitybased models) is found in Boßmann and Eser (2016).

${ }^{2}$ Note that activity-based models are also used within the field of land use and transportation modelling (Keirstead \& Sivakumar, 2012).
}

representation of the dependencies between loads within and between dwellings, to ensure that loads on the network are appropriately correlated in time. It is for this reason that activities are represented within such models - they provide a useful bottom-up variable with which to simulate domestic loads with an appropriate degree of time-diversity.

As well as their primary aim of supporting lowvoltage distribution network studies, the potential for such models to contribute to demand response studies has been recognised (Richardson, 2010; Widén \& Wäckelgård, 2010). In practice, however, the use of such models for this purpose has been limited to the 'technology' dimension, for example, assuming a certain proportion of thermal and wet appliances can be shifted based on introduction of smart controls (Ceseña, Good, \& Mancarella, 2015; Gudi, Wang, \& Devabhaktuni, 2012; Redpoint and Energy, 2012). Here we are interested in the potential to enhance these models to explore more of the socio-technical demand response space.

The need for improved tools to evaluate demand response

The primary aim of this paper is to examine how activity-based demand models may be enhanced to provide more useful tools for the assessment of demand response. A model is, by definition, a simplified representation of some complex system in the real world and so modellers are required to make certain simplifying assumptions about the system under investigation. Bottom-up models in particular are required to minimise model complexity as this allows for greater computational efficiency given the requirement to produce highresolution output for large numbers of households.

The areas in which modellers choose to simplify or include complexity can be largely a matter of judgement or intuition, and can often be less than explicit. These judgements and intuitions are, however, critical to the structure and function of a model and deserve careful scrutiny in light of the purpose the model is intended to serve. This paper therefore examines in particular the assumptions that are associated with activities, service expectations, and the presence and use of technologies. When we need to refer to these assumptions in general we shall use the broad term 'socio-technical assumptions'. 


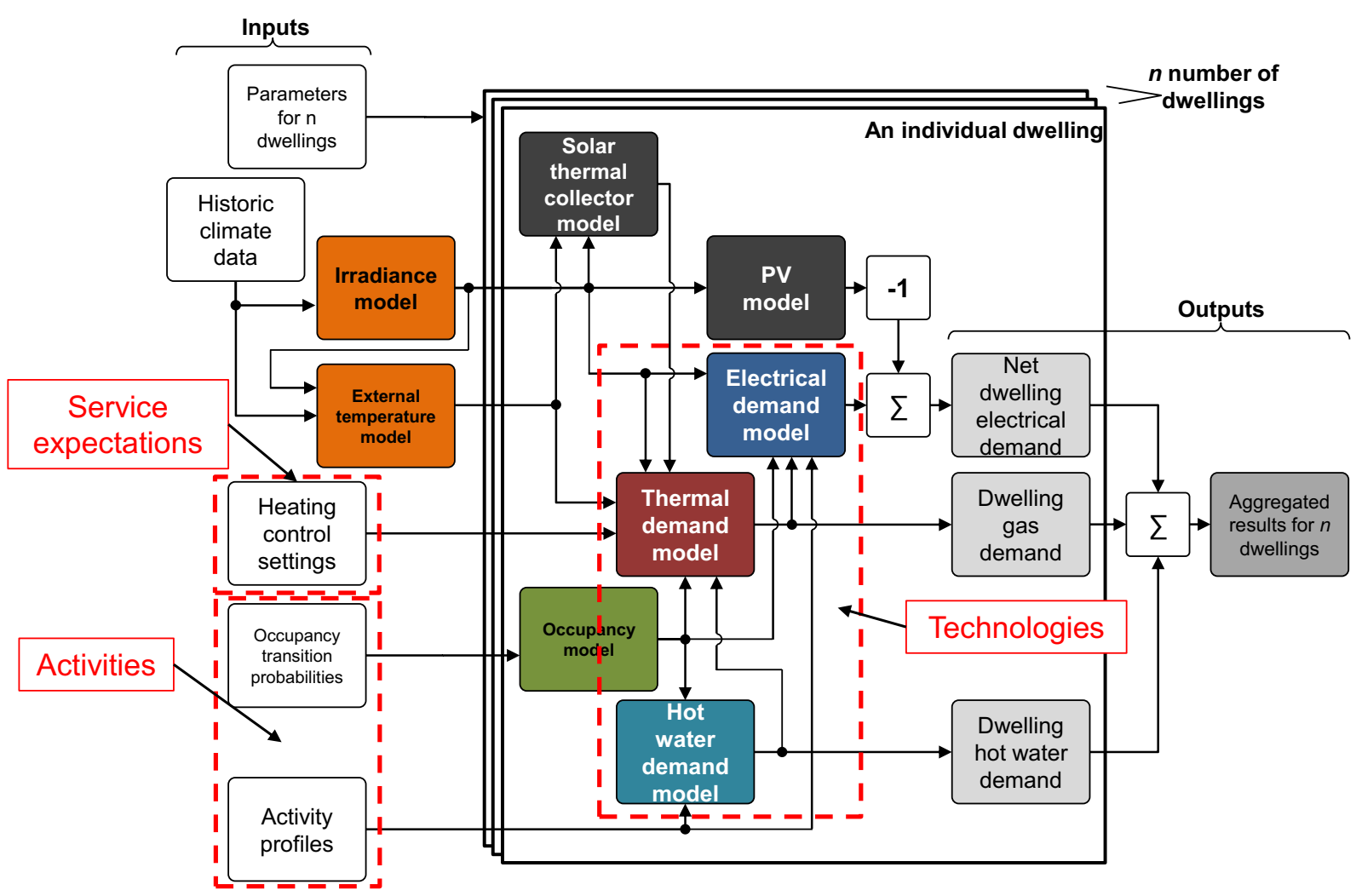

Fig. 1 Example high-level architecture of a bottom-up demand model (the CREST model)

In summary, the fundamental research questions of this paper are:

- What socio-technical assumptions are used in bottom-up activity-based models of domestic energy demand?

- What recommendations can be made for improving present modelling methods?

\section{Method}

Analytical framework: Three dimensions of demand response

Figure 2 offers a 'thinking tool' that helps visualise the potential socio-technical space of demand response. The three dimensional space describes different demand response mechanisms that can be explored: technology, service expectations and activities. Moving along any of these dimensions offers the potential for various demand response solutions
The 'technology change' dimension represents technology-enabled demand responses. In their purest form such responses draw on some form of storage. A smart fridge, for example, could use its thermal capacity and operating tolerance to deliver a response by altering

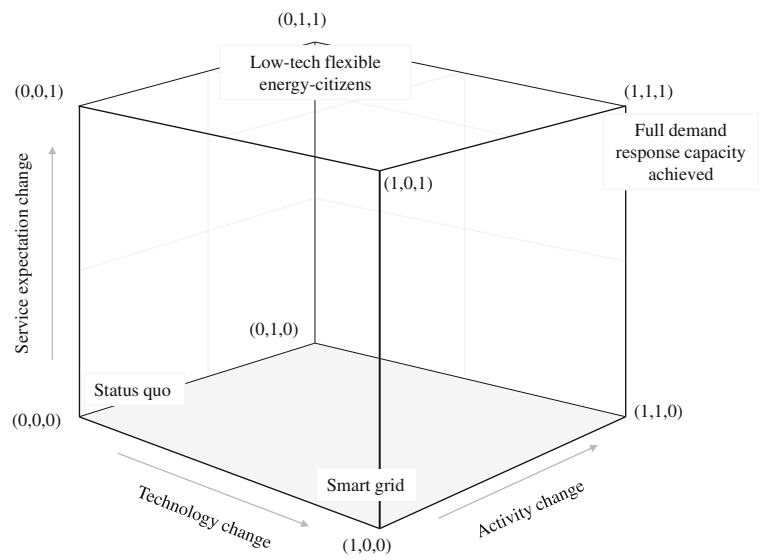

Fig. 2 Demand response space showing the total volume of possible demand response scenarios enabled by all hypothetical combinations of flexibility in technologies, activities and service expectations 
the timing of its compressor cycle without affecting the service or activities of its users.

The 'service expectation change' dimension implies a degree of flexibility in the delivery of energy services such that users might be affected but need not be active, such as altering thermostat settings and thereby relaxing the boundaries of thermal comfort. Finally, the 'activity change' dimension symbolises a change in either the timing or type of activity being undertaken and implies more participation from the user, such as postponing the laundry or preparing a hot meal at lunchtime rather than in the evening.

Adopting for the moment the simplifying assumption that it is possible to move along any one of these dimensions independently, ${ }^{3}$ we can imagine, for example, moving from the current status quo $(0,0,0)$, along the technology axis towards technology-enabled demand response $(1,0,0)$. Picture a smart grid with smart appliances, electric vehicles, distributed energy generation and storage technologies, and automated smart control systems managing the complex task of scheduling the operation, without impacting people's lives directly (Haider et al., 2016).

Alternatively, moving instead from the origin along the activity change axis to $(0,1,0)$ would require active rescheduling energy services, such as vacuum cleaning at a different time. A move towards the purely service expectation axis $(0,0,1)$, by comparison, would be a willingness to review meanings around cleanliness, reducing the frequency of vacuum cleaning or using a broom instead.

In practice these dimensions will overlap and this combination affords the greatest demand response potential. A technology enabled smart washing machine $(1,0,0)$ in combination with a willingness to change the time of use $(0,1,0)$ and overall reduction in the frequency of use $(0,0,1)$ would provide the greatest shifting potential.

\section{Reference models}

To achieve our aim of examining the socio-technical assumptions in activity-based demand models, we focus on models that meet the following three criteria:

\footnotetext{
$\overline{3}$ In practice, moving along one dimension cannot be done completely independently of the others; inevitably change in one direction will affect change in the other directions also. As an example from a related field, technological improvement in energy efficiency is associated with a 'rebound effect' where service expectations increase. So while this cube is shown as a completely open space, in practice it is more like a three-dimensional maze with pathways that define the sub-set of the total possible space that can actually be reached.
}

- simulate energy demand at household level,

- are based on some form of activity data

- have the potential to be used for demand response studies

We have selected five models meeting the above criteria for detailed review. These are listed in Table 1.

There are related models that have not been included in the review because they do not meet the above criteria. For example, some purely activity-based models do not simulate actual household energy demand (Aerts, Minnen, Glorieux, Wouters, \& Descamps, 2014; López-Rodríguez, Santiago, Trillo-Montero, Torriti, \& Moreno-Munoz, 2013; Wilke, Haldi, Scartezzini, \& Robinson, 2013), while Paatero and Lund (2006) simulate appliance use based on deriving switch-on probabilities from monitored electricity consumption data, rather than activity information.

Identification of assumptions commonly made between these models is based on a critical assessment of the papers that describe each model, with explicit reference to these where appropriate. Where assumptions have not been explicitly referenced we base our assessment on the CREST model (McKenna \& Thomson, 2016; Richardson et al., 2010). This is open source and freely available for download, and developed in Excel VBA which makes scrutiny of its underlying code easily accessible by other researchers. The assumptions it is built on, both explicit and implicit, are as a result more accessible than for models where the code is not available. In addition, its open-source nature has meant that it has been widely adopted and developed in the academic and industrial community, ${ }^{4}$ and, by extension, so too its underlying socio-technical assumptions. The 'data' used to derive the results reported in this paper are therefore the published papers describing the models, as well as the published code of the CREST model.

We have separated the assumptions out into the three 'dimensions' introduced in the previous section: technology, service expectations and activities. To be clear,

- The term 'activities' here refers not only to activities as defined in national time use surveys (Torriti, 2014) but also the related concepts of occupancy, active-occupancy (where a resident is at home and active), and broader assumptions about the residents of a dwelling.

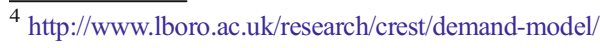


Table 1 list of models reviewed

\begin{tabular}{|c|c|}
\hline Model name & References \\
\hline $\begin{array}{l}\text { StROBe (Stochastic Residential Occupant Behaviour) and IDEAS } \\
\text { (Integrated District Energy Assessment Simulations) }\end{array}$ & Baetens et al., 2012, 2015; Baetens \& Saelens, 2016 \\
\hline Multi-energy building energy demand model & Good, Zhang, Navarro-Espinosa, \& Mancarella, 2015b \\
\hline $\begin{array}{l}\text { A highly resolved modelling technique to simulate residential } \\
\text { power demand }\end{array}$ & Muratori, Roberts, Sioshansi, Marano, \& Rizzoni, 2013 \\
\hline CREST Demand model & $\begin{array}{l}\text { McKenna \& Thomson, 2015; Richardson, Thomson, } \\
\text { Infield, \& Clifford, } 2010\end{array}$ \\
\hline $\begin{array}{l}\text { A high-resolution stochastic model of domestic activity patterns } \\
\text { and electricity demand }\end{array}$ & Widén \& Wäckelgård, 2010 \\
\hline
\end{tabular}

- 'Technology' can refer to appliances, lighting, water fixtures, heating, ventilation and cooling systems, solar thermal and photovoltaics, the building thermal envelope, etc. In practice, however, the focus is predominantly on appliances, as simulating their usage is a primary output of such models.

- 'Service expectation' refers to the quantifiable level of service expected by a resident from a technology e.g. a thermostat set-point or the amount of time the heating is on.

The assumptions that are judged to be most critical to our focus on demand response are described below and their relevance is discussed in more detail in the Discussion section. We have however made an effort to list socio-technical assumptions more broadly in the hope that this may be a useful resource for those interested in improving such models more generally. We also note that this is a qualitative assessment of the assumptions; a quantitative assessment is out of the scope of this work, but we will return to suggestions how to address them in the Discussion section.

\section{Analysis of model assumptions}

Activities

\section{Assumption 1: Time use data represents energy use}

The primary sources of data for 'activities' in the models reviewed here are national time use studies (Lader, Short, \& Gershuny, 2006), which sample large sections of a population with self-administered time use diaries. Their use for energy research has long been suggested (Boardman, 1990), but only in recent years has time use data entered models like the ones reviewed here. Having not being collected with this purpose in mind, however, the data has at least four failings.

Firstly, the Harmonised European Time Use Survey (HETUS), which seeks to provide consistency of time use codes over time and between member states, does not differentiate between 'energy intensive' and 'low energy' alternatives of the same activity. "Food preparation" (code 311) does not distinguish between a three-course cooked meal and the cutting up of an apple. Similarly, "Laundry" (code 331) could refer to the running of a tumble dryer or hanging washing on a line. Reverse-engineering the load profile from these generic activity codes is therefore subject to systematic errors. Associating appliance use with activities requires more refined data collection instruments.

A second limitation is the poor coverage of parallel and overlapping activities. The HETUS uses 'primary' and 'secondary' activities. Some 'energy related activities' may however not be captured as either. Bundled activities, such as listening to the radio while ironing with the lights on, do not get captured as collective sets. Many energy intensive activities do however happen in periods of intensive activity (Durand-Daubin, 2013).

Thirdly, the definition of an activity as being made up of 10-min episodes has a strong influence on which activities are captured and which are omitted. Short activities, like boiling a kettle or opening a window do not warrant recording for many people, yet have considerable significance for energy models.

Fourth, time use research is focused on the individual, whereas electricity use in households is the product of collective (and interdependent) activities resulting from complicated household dynamics. Some time use studies have begun to collect data from all household participants, but available data is limited. 
Assumption 2: Activities transition stochastically (Markov-chains)

National time use surveys comprise quantities of data that are sufficiently large that their wholesale replication and direct use within models has been avoided. Instead, models include only a relatively small amount of data which statistically summarises certain properties of the original data, and which are then used to generate synthetic sequences of activities in the quantities required. All five models in Table 1 generate synthetic sequences of activities using the Markov-chain technique, whereby a sequence of discrete states is simulated, based on the observed probabilities in the time use data, and by means of which people transition between states by continuously moving from one time step to the next. The sequence of synthetic activity states is determined by a stochastic process: a random number is generated and compared with the observed transition probabilities to determine the change of state. Over a large number of runs, the synthetic output will have aggregated statistical properties that can closely match the original data (McKenna, Krawczynski, \& Thomson, 2015).

While the Markov-chain technique provides a number of benefits, such as enabling models to be selfcontained and thus supporting their distribution and use, they are inherently based on certain implicit socio-technical assumptions. Most critically, they are based on the assumption that activities are random variables that depend on a fixed number of independent variables such as: day of the week, total number of residents in a household, and activity states in a fixed number of previous time periods. While transition probabilities may vary in time, these dependencies do not. Furthermore, they are assumed to be the same for all activities i.e. the factors that affect food preparation are constant throughout the day and are the same as those that affect commuting. While this is arguably an adequate simplification for generating synthetic activity sequences which match the probability distribution of the original time use data, it may not fully capture more complex activity sequences (transitions spanning several time periods and activities) and may thus underestimate clustering effects, which could have a significant effect on energy demand profiles. This limits a model's capabilities to simulate demand response, as discussed further in the Discussion section.
Assumption 3: We are all the same

Dwellings are assumed to be occupied only by permanent residents of those dwellings, and they are assumed to be 'average' adults. By not distinguishing households and their residents by characteristics such as gender, age, health, employment status, work patterns or indeed whether children, elderly relatives, guests or others are present, factors are omitted that may have strong associations with energy demand. Another risk is that the characteristics of an average resident may have little meaning for demand response purposes if few people, in practice, conform to the characteristics of the average: considerable potential for change may be lost.

\section{Further assumptions}

Further oversimplified assumptions include that residents perform one activity at a time and that, when performing an activity, a resident is in a discrete state, or, in other words, activities are not combined so that, for example, a continuous combination of childcare and watching TV is not a recognised state, which makes it impossible to account for the use of multiple appliances associated with activities performed in parallel. This implies the potential under-estimation of concurrent appliance usage and, hence, peak energy demand. Although this is likely less of an issue for aggregations of dwellings and so adequate for the purposes of network modelling, it does not provide the granularity necessary for estimating demand response.

Furthermore, a 'state' is considered to fully and completely describe an activity, such that the activity state of 'cooking' completely describes the whole of the activity, regardless of whether they are making salad or using the oven and residents in the same state are indistinguishable from one another, at least in terms of their activity.

Finally, in dwellings with multiple residents, the activity states of individual residents are conflated, or merged, as a combined activity state for the whole dwelling. For example, in a two-resident dwelling, the combined state could be described as 'one resident at home and one resident awake'. However, this could represent more than one combination of individual activity states, as follows: it could be that one resident is at home and awake, and one is not at home and not awake (which will probably result in variable electricity 
demand within the dwelling), or it could be that one resident is awake but not at home, and one is not awake but at home (which will only involve baseload consumption). Though quite different, the individual states are conflated, and the ability to perform the reverse process is lost i.e. it is not possible to assign a disaggregation of the combined state to the individual residents. As is clear, there is a risk of incorrectly anticipating the energy consumption in the home.

A focus on 'states' may also serve to obscure the potential for learning and change over time. As pointed out previously people live in more or less dynamic interaction with the systems and appliances in their homes and it is reasonable to expect demand response to change over time - in scale, type and duration - as they grow accustomed to the concept, the tariffs and the activities involved and as the technologies involved change and develop. Hence the importance attached to customer education and experimentation in demand response programmes (Darby \& McKenna, 2012; Jessoe \& Rapson, 2014; Stromback, Dromacque, Yassin, \& VaasaETT, 2011).

Technology

\section{Assumption 1: Appliances are directly linked to activities}

Simulating activities is a primary requirement of activity-based demand modelling and the models reviewed here make fundamental assumptions about the causal association between activities and appliance use. For example:

- While activities can involve any number of associated appliances, appliances are assumed to be associated with one activity only (Baetens \& Saelens, 2015; Good et al., 2015b; Muratori et al., 2013; Richardson et al., 2010; Widén \& Wäckelgård, 2010) and this precludes their usage in association with another activity.

- Appliances are not considered to be 'switched on' unless their associated activity is taking place.

- The dependence of appliance-usage on activities is time-homogeneous (Baetens \& Saelens, 2015; Good et al., 2015b; Muratori et al., 2013; Richardson et al., 2010; Widén \& Wäckelgård, 2010), which means that the probability distribution of an appliance being switched on is the same as its associated activity.

The risk of all three assumptions is that appliances may be simulated with a temporal usage profile that will be an (inaccurate) function of the associated activity. If, for example, the oven appliance is associated with food preparation then it will be modelled to be switched on in the morning when people have reported preparing food for breakfast, despite the fact that in practice they are much less likely to be using the oven for food preparation in the morning than in the evening. The issue is that these assumptions are made in the absence of data. There is an absence of good evidence about the relationships between activities and appliances, meaning they are not well understood, and their specification within models remains largely a matter of judgement. The implications of this are discussed further in the Discussion section.

\section{Assumption 2: Stochastic appliance ownership and use}

Appliances are assumed to be independent of other appliances, both in terms of the probability of being present within a dwelling and of being used. For example, the presence and sequential use of a washing machine and a drier are highly correlated but this is not represented in the models above. The risk is that a model produces combinations of appliances that are present in dwellings and their usage that, while correct on average, might include specific cases that occur rarely or never in reality. Furthermore, appliances are assumed to be average (Baetens \& Saelens, 2015; Good et al., 2015b; Muratori et al., 2013; Richardson et al., 2010; Widén \& Wäckelgård, 2010) both in terms of type of appliance (e.g. power characteristics) and how frequently they are used (e.g. switch-on probabilities calibrated in relation to national average energy demand estimates for an appliance type). The risk is that diversity of applianceuse may not be accurately captured.

\section{Assumption 3: Appliances are used the same in every home}

Another simplifying assumption is that applianceactivity dependencies are the same for every dwelling. Although, in practice, certain types of household or resident may be more or less likely to own certain types of appliances and to use them to a greater or lesser extent, this is not represented in the models. If there is 
a diversity of such associations both within and between dwellings, the risk is that models are not accurately representing this.

\section{Service expectations}

\section{Assumption 1: Thermal comfort expectation is constant}

Previous sections have described how appliance use is modelled by associating the probability of being switched on with activities performed by household residents. The use of heating technologies, however, is modelled differently, and is instead associated with the representation of a service expectation: thermal comfort. Thermostat set-points are modelled as random variables that are assigned to a dwelling based on empirical probability distributions, and indoor temperatures are explicitly modelled such that a heating or cooling system is operated to meet a given thermal comfort expectation of the dwelling. ${ }^{5}$ A benefit of this approach is that it explicitly captures the fact that, regardless of dwelling or heating/cooling technologies, people have different thermal comfort expectations and this contributes to some of the wide diversity of energy use associated with indoor environments. Thermostat settings are, however, modelled as an independent variable and, once assigned, remain constant. Factors that may have an important effect on thermal comfort expectations risk being omitted. These could include:

- type or presence of residents (e.g. all types of households have the same service expectation; all residents within a dwelling have the same expectations to be met in all rooms) ${ }^{6}$;

- activities (no concept of different levels of lighting or heating needed for different activities);

- potential relationships between different service expectations (e.g. people who have higher indoor temperature set-points might have correspondingly higher washing machine set-points);

- exogenous variables such as external temperature, irradiance, or demand response signal.

\footnotetext{
${ }^{5}$ If empirical data is not available on thermostat set-points, they are assigned based on average or arbitrary values.

${ }^{6}$ We note that Baetens et al. explicitly model space heating settings as dependent on dwelling occupancy (Baetens \& Saelens, 2015).
}

Assumption 2: All other service expectations are stochastic

Service expectations not associated with thermal comfort, such as the frequency of washing machine use or its temperature are a function of stochastic processes of assigning switch-on probabilities, rather than the result of some households having different expectations of cleanliness or hygiene and so are based on statistical probabilities rather than empirical evidence. As discussed further in the Discussion section, the issue is that lack of representation within models of service expectations related to energy use limits the capability of such models to evaluate the potential and impact of demand response: that is, if new washing materials and/ or changed social norms bring down wash temperatures, it may have a dramatically greater effect on consumption than a change in the number of washes.

\section{Discussion}

The assumptions listed above relate to activity, technology and service expectations, all of which have a bearing on how demand response may be achieved. Building on some of these findings, this section develops recommendations for how activity-based models may be enhanced in each of these three areas.

The next section discusses the missing link between activities and appliance use, the following section proposes means to better reflect the impact of technologies on demand response and the final section elaborates on the importance of representing service expectations.

Interconnected activities and appliances

To what extent are people willing and able to change the timing of their activities? Activities are highly interconnected, and time-shifting one activity will have an impact on others in complex ways. Activity-based demand models ignore this complexity, and make the simplifying assumption that activities are dependent only on what a person did in the previous time step. While this type of simplification has been reasonable for the purposes of accounting for demand diversity within lowvoltage network studies, it is not amenable to accounting for demand response. For demand response studies, there is a need, therefore, to better understand dependencies among activities, such that it is possible to 
evaluate the impact of removing, adding, or timeshifting them.

Recognising the limitations above, there is a move towards more complex models of activity (Aerts et al., 2014; Flett \& Kelly, 2016; Wilke et al., 2013). These are characterised by i) the use of higher-order Markovchains, or 'survival models' of activities, and ii) by providing greater detail about the characteristics of the household occupants and their occupancy patterns. The aim of these modifications is to simulate patterns of occupancy more accurately, to move away from the assumption of occupants as 'average' adults, and to create more meaningful characterisations of households e.g. single working male, retired couple, etc. The challenge with all such efforts to provide greater accuracy and detail on the simulated household is that it implies a greater data burden as larger sample sizes are needed to derive meaningful activity statistics (McKenna et al., 2015).

In improving the representation of the associations and dependencies of activities, such models are making progress towards bottom-up models that can simulate demand response, though this remains to be proven. While it may be possible to capture the complexity of interconnected activities endogenously, by changing the simplifying assumptions and basing new ones on data that explicitly captures dependencies, this is a challenging task due to the complexity of the subject, though one that merits further exploration (McKenna, Higginson, Hargreaves, Chilvers, \& Thomson, 2016).

Time use activity data, for example, implicitly captures many of the complexities of people's connected activities. Such data have been collected for many decades in multi-national studies (Gershuny \& Sullivan, 2003). Two methodological additions are needed for these data to address questions of demand side flexibility. Firstly, activities need to be associated with actual electricity loads at household level. For this the collection tool (conventionally paper diaries) could be complemented with smart meter readings for a given household during this period. Secondly, since flexibility is a dynamic property, a dynamic collection of changes to demand (and activities) in response to interventions could reveal extent, cost and conditions under which flexibility is forthcoming (Grunewald, 2016).

The Meter study collects such data using electricity recorders with $1 \mathrm{~s}$ resolution and a research app to collect activities from all household members above the age of eight (Grunewald, 2015). The app based approach simplifies participation and lends itself to interactive testing of responses to price signals and other interventions, such as a change in information or technology. To deliver robust findings such data needs to be collected at a large scale and validated against representative control groups.

Presently, time use data tends to be collected for single days only. Capturing multiple days would illuminate some of the intra-week rhythms and response patterns potentially present in people's everyday lives. Furthermore, repeated deployment of such data collection will provide detailed insights into trends over time, such as the adoption of technologies and changes in social norms and practices (for instance the impact of on demand TV).

This data could be used within activity-based models to differentiate between households of different characteristics.

\section{Describing appliance usage}

Technology-change, i.e. replacing specific appliances or loads with smarter alternatives, is among the most straightforward applications of activity-based models to evaluate load profile changes. Modelling new physical components (e.g. a heat pump rather than a gas boiler) and the consequent change in operating pattern is a reasonably well-established modelling task e.g. (Kelly \& Beausoleil-Morrison, 2008). However, there may well be issues with the timing and extent of technology use when a heating system is replaced by new technologies: a gas central heating system, heat pump, smart electric thermal storage heater, biomass stove, micro-CHP system or Passivhaus-standard refurbishment have characteristics that mean they cannot be viewed as functionally equivalent, although all are intended to result in a comfortable dwelling (Isaksson, 2011; Skjølsvold \& Ryghaug, 2015). Rather, they offer different types of service, with different response times and types of control, which may in turn influence a range of household activities and characteristics, such as bedtimes, laundry routines and allocation of space for different activities and for storage tanks or fuel.

Considerations such as these again call into question several of the assumptions listed above, such as that:

- Appliances are associated with one activity.

- The dependence of appliance-usage on activities is time-homogeneous. 
- Appliance-activity dependencies are the same for every dwelling.

These assumptions, and the way they are specifically implemented in models, often seem to be largely a matter of modellers' intuition. While the timing of activities is well understood through national time use surveys (Torriti, 2014), and there is an increase in data on, and understanding of, the timing of individual appliance usage (Zimmerman et al., 2012), this cannot be said of the relationship between the two.

There is little recognition of the socio-technical nature of appliance adoption and use, and their potential impact on service expectations. The simulation of appliance usage in activity-based demand models is based on an explicit assumed causal one-way relationship between activities and appliances, yet there is a distinct lack of data on which to base this. A consequence is that such models produce appliance usage profiles that may not capture the full impact of new technology adoption.

From the perspective of demand response studies, the timing of appliance energy use is of primary interest, followed by estimates of the impact of changing that timing. Yet, where the technology investigated is assumed to be activity-dependent, activity-based models do not have a firm evidence base to support such studies. This highlights a gap in the current understanding of energy use that is fundamental to the task of evaluating the scope for demand response in power systems. There is, as a result, a clear requirement for data that fills this gap. While there are considerable data collection efforts in activities and appliance usage separately, there is a need now for large-scale data collection exercises that help to understand how they are related, thereby increasing the overall value of the data when viewed as $a$ whole. The Meter study referred to previously is a step in this direction.

\section{Representing service expectations 'feedback loops'}

Service expectations, as discussed previously, form an important dimension of the demand response space. Even so-called 'technical' demand response solutions require householders to engage, whether to accept their data being shared, adapt to new tariffs and learn to manage their comfort levels using new technologies. However, reduced expectations, such as a willingness to settle for a cold meal instead of a hot one, doing laundry at lower temperature settings, or showering rather than bathing, could enhance the scope for demand response even more. The regularity with which people might be expected to be flexible also depends on their service expectations - what changes could be called upon on a daily basis, possibly becoming part of new practices, or are responses limited to extreme conditions such as the threat of a blackout? ${ }^{7}$

The current state of the art in activity-based modelling allows for exploration of variations in thermal comfort expectations, making it possible to quantify the impact of deviations from typical thermostat set-points and 'dead bands' and estimating the value this could have within the wider power system. This requires the service expectation to be represented within the model, and then compared with the service variable, which acts as the signal that controls the technology delivering the service. In other words, if the indoor winter temperature requirement is $19^{\circ} \mathrm{C}$ in one home and $21^{\circ} \mathrm{C}$ in another (the service expectation), models will 'switch on' the heating as required to keep those buildings, with their particular thermal properties in those climactic conditions, at that internal temperature, providing variation across different households. One way of viewing this is as a service expectation 'feedback loop' which drives the extent to which technologies are used to achieve the required level of service. Accounting for the diversity of service expectations in the population is a means for models to account for the diversity in energy demand in the population.

While it is obviously useful and relevant to be able to model thermal comfort (and, therefore, thermal energy demand) in this way, other sorts of service expectations and the associated feedback loops which drive electricity use, are not represented. This makes it impossible to quantify the potential impact of demand response changes along this dimension. Some models make an effort to include a representation of variability in demand e.g. hot water draws and duration of showers, but do not include the service representation nor a feedback loop. As a result, while it is possible to model what would happen as a result of the change, there is no way of understanding the impact on people's lives implied by the change.

This leads to the conclusion that for demand response studies there is a value in including further explicit representations of service expectation feedback loops within activity-based demand models. This in turn leads

\footnotetext{
${ }^{7}$ Compelling examples of the latter are offered by Goldman, Barbose,
} and Eto (2002) and Costa (2013). 
to the following research question: what are the critical service expectations in households, how can they be specified, represented and quantified (perhaps even if in the same simplified manner as thermal comfort), and furthermore how do these vary within and between households? While clearly this would still involve simplification of highly complex social practices, it would nonetheless be a considerable step forward in improving activity-based demand models and more generally in incorporating insights from the social sciences into engineering models of demand response.

\section{Conclusions}

The aim of this paper was to expose socio-technical assumptions in current activity-based demand models and to make suggestions to overcome the limitations they pose. Our three key findings are:

1. Present methods assume a causal relationship between activities and appliances. In the absence of data, this specification is arbitrary and left to modellers' intuition. Present methods could be improved given data that describes this relationship.

2. Present methods lack representations of service expectations, beyond thermal comfort. Service expectations are an important determinant of energy use within homes, and could offer considerable potential for demand response. Present methods could be improved by more and better representations of service expectations.

3. Present methods are based on time use data for a single person for a single day. As it is for a single day, this data does not capture the inherent flexibility of people's activities. Present methods could be improved given time use data that covers multiple days, and ideally shows how people's activities change in response to a demand response signal.To estimate residential demand response capacity in a given electricity system, there is a value in considering the scope for flexibility in people's service expectations and activities, their interplay, and the coevolution of expectations and activities with technological change. This substantially enlarges the possibility space for demand response evaluation.

Activity-based models include representations of activities, service expectations and technologies and so have a promising high-level architecture for exploring the socio-technical demand response space. Despite their promise, though, there is at present little exploration of demand response potential beyond a focus on technology change, and there are also shortcomings in such models. In particular, activity-based models tend to rely on some questionable assumptions about the nature of electricity demand and the relationships between technology, activity and energy services. An assessment of these sociotechnical assumptions leads to three conclusions regarding specific areas for improvement to realise more effective activity-based demand response modelling.

Current activity-based models explicitly assume a causal one-way relationship between activities and appliances. Yet there is a distinct lack of data on which to base this, with the risk of incorrect simulated appliance profiles. There is a requirement for collection and understanding of data describing the relationship between activities and appliance energy use, and how this varies within and between households.

Activity-based models lack representations of the service expectations which, to a large degree, explain the variation of energy use across contexts. Because these are not represented, there is no way of quantifying the potential impact of demand response changes associated with service expectation change. This leads to a second area for enquiry: how can service expectations in households best be specified, represented, and quantified in ways that are both suitable for modelling and reflect established and emerging routines and flexibilities, insofar as these can be captured?

Finally, for the purposes of activity-based modelling of demand response there is a value in time use activity data that is longitudinal, i.e. covering the same households over lengthy periods of time and ideally supplemented by information about how households react to experiencing a price-based or other form of demand response signal.

\section{Acknowledgements}

The authors gratefully acknowledge funding from:

- The Oxford Martin School, University of Oxford, through the Oxford Martin Programme on Integrating Renewable Energy. The Oxford Martin School is a world-leading centre of pioneering research that addresses global challenges. Visit: www. oxfordmartin.ox.ac.uk for more information. 
- The RealValue project, funded by the European Union's Horizon 2020 research and innovation programme under grant agreement No. 646116. Visit: http://www.realvalueproject.com/ for more information.

- The EPSRC Early Career Fellowship scheme. Ref. EP/M024652/1.

- The UK Energy Research Centre.

Compliance with ethical standards Underlying research materials can be obtained directly from the authors on request.

\section{Conflict of Interest None.}

Open Access This article is distributed under the terms of the Creative Commons Attribution 4.0 International License (http:// creativecommons.org/licenses/by/4.0/), which permits unrestricted use, distribution, and reproduction in any medium, provided you give appropriate credit to the original author(s) and the source, provide a link to the Creative Commons license, and indicate if changes were made.

\section{References}

Aerts, D., Minnen, J., Glorieux, I., Wouters, I., \& Descamps, F. (2014). A method for the identification and modelling of realistic domestic occupancy sequences for building energy demand simulations and peer comparison. Building and Environment, 75, 67-78. doi:10.1016/j.buildenv.2014.01.021.

Aghaei, J., \& Alizadeh, M.-I. (2013). Demand response in smart electricity grids equipped with renewable energy sources: A review. Renewable and Sustainable Energy Reviews, 18, 64 72. doi:10.1016/j.rser.2012.09.019.

Albadi, M. H., \& El-Saadany, E. F. (2008). A summary of demand response in electricity markets. Electric Power Systems Research, 78, 1989-1996. doi:10.1016/j.epsr.2008.04.002.

Baborska-Narozny, M., Stevenson, F., \& Ziyad, F. J. (2016). User learning and emerging practices in relation to innovative technologies: A case study of domestic photovoltaic systems in the UK. Energy Res. Soc. Sci., 13, 24-37.

Baetens, R., \& Saelens, D. (2015). Modelling uncertainty in district energy simulations by stochastic residential occupant behaviour. Journal of Building Performance Simulation, 117. doi:10.1080/19401493.2015.1070203.

Baetens, R., \& Saelens, D. (2016). Modelling uncertainty in district energy simulations by stochastic residential occupant behaviour. Journal of Building Performance Simulation, 9, 431-447. doi:10.1080/19401493.2015.1070203.

Baetens, R., Coninck, R. D., Roy, J. V., Verbruggen, B., Driesen, J., Helsen, L., \& Saelens, D. (2012). Assessing electrical bottlenecks at feeder level for residential net zero-energy buildings by integrated system simulation. Applied Energy, 96, 74-83. doi:10.1016/j.apenergy.2011.12.098.

Baetens, R., De Coninck, R., Jorissen, F., Picard, D., Helsen, L., Saelens, D., 2015. Openideas-an open framework for integrated district energy simulations, in: Building Simulation.

Blumsack, S., \& Fernandez, A. (2012). Ready or not, here comes the smart grid! Energy, 37, 61-68.
Boardman, B., 1990. Fuel poverty and the greenhouse effect. Glasg. Heatwise Glasg.

Boßmann, T., \& Eser, E. J. (2016). Model-based assessment of demand-response measures-A comprehensive literature review. Renewable and Sustainable Energy Reviews, 57, 16371656. doi:10.1016/j.rser.2015.12.031.

Budischak, C., Sewell, D., Thomson, H., Mach, L., Veron, D. E., \& Kempton, W. (2013). Cost-minimized combinations of wind power, solar power and electrochemical storage, powering the grid up to $99.9 \%$ of the time. Journal of Power Sources, 225, 60-74. doi:10.1016/j.jpowsour.2012.09.054.

Ceseña, E. A. M., Good, N., \& Mancarella, P. (2015). Electrical network capacity support from demand side response: Techno-economic assessment of potential business cases for small commercial and residential end-users. Energy Policy, 82, 222-232. doi:10.1016/j.enpol.2015.03.012.

Costa, F., 2013. Can Rationing Affect Long Run Behavior? Evidence from Brazil. Evid. Braz. June 2013.

Darby, S. (2006). Social learning and public policy: Lessons from an energy-conscious village. Energy Policy, 34, 2929-2940.

Darby, S. J., \& McKenna, E. (2012). Social implications of residential demand response in cool temperate climates. Energy Policy, 49, 759-769. doi:10.1016/j.enpol.2012.07.026.

Delucchi, M. A., \& Jacobson, M. Z. (2011). Providing all global energy with wind, water, and solar power, part II: Reliability, system and transmission costs, and policies. Energy Policy, 39, 1170-1190. doi:10.1016/j.enpol.2010.11.045.

Durand-Daubin, M., 2013. Household activities through various lenses: crossing surveys, diaries and electric consumption.

Elliston, B., Diesendorf, M., \& MacGill, I. (2012). Simulations of scenarios with $100 \%$ renewable electricity in the Australian National Electricity Market. Energy Policy, 45, 606-613.

Fell, M. J., Shipworth, D., Huebner, G. M., \& Elwell, C. A. (2015). Public acceptability of domestic demand-side response in great Britain: The role of automation and direct load control. Energy Res. Soc. Sci., 9, 72-84.

Flett, G., \& Kelly, N. (2016). An occupant-differentiated, higherorder Markov chain method for prediction of domestic occupancy. Energy and Buildings, 125, 219-230. doi:10.1016/j. enbuild.2016.05.015.

Gershuny, J., \& Sullivan, O. (2003). Time use, gender, and public policy regimes. Soc. Polit. Int. Stud. Gend. State Soc., 10, 205-228.

Glad, W. (2012). Housing renovation and energy systems: The need for social learning. Building Research and Information, 40, 274-289.

Goldman, C. A., Barbose, G. L., \& Eto, J. H. (2002). California customer load reductions during the electricity crisis: Did they help to keep the lights on? J. Ind. Compet. Trade, 2, 113-142.

Good, N., Karangelos, E., Navarro-Espinosa, A., \& Mancarella, P. (2015a). Optimization under uncertainty of thermal storagebased flexible demand response with quantification of residential users' discomfort. IEEE trans. Smart Grid, 6, 23332342. doi:10.1109/TSG.2015.2399974.

Good, N., Zhang, L., Navarro-Espinosa, A., \& Mancarella, P. (2015b). High resolution modelling of multi-energy domestic demand profiles. Applied Energy, 137, 193-210. doi:10.1016 j.apenergy.2014.10.028.

Gram-Hanssen, K., Darby, S.J., 2016. Are "home" and 'smart' contradictory concepts or fluid positions that will converge? 
Grunewald, P., 2015. "Measuring and Evaluating Time-Use and Electricity-Use Relationships (Meter)." Early Career Fellowship Ref. EP/M024652/1. Engineering and Physical Sciences Research Council (EPSRC).

Grunewald, P., 2016. Flexibility in supply and demand, in: DEMAND Centre Conference.

Gudi, N., Wang, L., \& Devabhaktuni, V. (2012). A demand side management based simulation platform incorporating heuristic optimization for management of household appliances. International Journal of Electrical Power \& Energy Systems, 43, 185-193. doi:10.1016/j.ijepes.2012.05.023.

Haider, H. T., See, O. H., \& Elmenreich, W. (2016). A review of residential demand response of smart grid. Renewable and Sustainable Energy Reviews, 59, 166-178. doi:10.1016/j. rser.2016.01.016.

Higginson, S., McKenna, E., Hargreaves, T., Chilvers, J., Thomson, M., 2015. Diagramming social practice theory: An interdisciplinary experiment exploring practices as networks. (In press). Indoor Built Environ.

Isaksson, C., 2011. From a passive to an active house, in: World Renewable Energy Congress-Sweden; 8-13 May; 2011; Linköping; Sweden. Linköping University Electronic Press, pp. 1789-1796.

Janda, K. B. (2014). Building communities and social potential: Between and beyond organizations and individuals in commercial properties. Energy Policy, 67, 48-55.

Jessoe, K., \& Rapson, D. (2014). Knowledge is (less) power: Experimental evidence from residential energy use. The American Economic Review, 104, 1417-1438.

Keirstead, J., Jennings, M., Sivakumar, A.(2012). A review of urban energy system models:Approaches, challenges and opportunities. Renewable and Sustainable Energy Reviews 16(6):3847-3866.

Kelly, N., Beausoleil-Morrison, I., 2008. Specifications for modelling fuel cell and combustion-based residential cogeneration devices within whole-building simulation programs (IEA Annex 42 subtask B report). Accessed 6 May 2014.

Lader, D., Short, S., Gershuny, J., 2006. The time use survey, 2005. We Spend Our Time Lond. Off. Natl. Stat. URL Httpwww Timeuse OrginformationpublicationsdocsTimeUse2005 Pdf Luettu 15, 2009.

López-Rodríguez, M. A., Santiago, I., Trillo-Montero, D., Torriti, J., \& Moreno-Munoz, A. (2013). Analysis and modeling of active occupancy of the residential sector in Spain: An indicator of residential electricity consumption. Energy Policy, 62, 742-751. doi:10.1016/j.enpol.2013.07.095.

Lutzenhiser, L., Bender, S., 2008. The "Average American" unmasked: Social structure and differences in household energy use and carbon emissions.

McKenna, E., Thomson, M., 2015. High-resolution integrated thermal-electrical domestic demand model. (Software download). Loughborough University.

McKenna, E., \& Thomson, M. (2016). High-resolution stochastic integrated thermal-electrical domestic demand model. Applied Energy, 165, 445-461. doi:10.1016/j. apenergy.2015.12.089.

McKenna, E., Krawczynski, M., \& Thomson, M. (2015). Fourstate domestic building occupancy model for energy demand simulations. Energy and Buildings, 96, 30-39. doi:10.1016/j. enbuild.2015.03.013.
McKenna, E., Higginson, S., Hargreaves, T., Chilvers, J., Thomson, M., 2016. Exploratory analysis of time-use activity data using network theory, in: Proceedings of the DEMAND Conference 2016. Lancaster, UK, p. 20.

Muratori, M., Roberts, M. C., Sioshansi, R., Marano, V., \& Rizzoni, G. (2013). A highly resolved modeling technique to simulate residential power demand. Applied Energy, 107, 465-473. doi:10.1016/j.apenergy.2013.02.057.

Nicol, J. F., \& Humphreys, M. A. (2002). Adaptive thermal comfort and sustainable thermal standards for buildings. Energy and Buildings, 34, 563-572.

Paatero, J. V., \& Lund, P. D. (2006). A model for generating household electricity load profiles. International Journal of Energy Research, 30, 273-290. doi:10.1002 /er.1136.

Powells, G., Bulkeley, H., Bell, S., \& Judson, E. (2014). Peak electricity demand and the flexibility of everyday life. Geoforum, 55, 43-52.

Rasmussen, M. G., Andresen, G. B., \& Greiner, M. (2012). Storage and balancing synergies in a fully or highly renewable pan-European power system. Energy Policy, 51, 642651. doi:10.1016/j.enpol.2012.09.009.

Redpoint and Energy, E, 2012. Electricity System Analysis future system benefits from selected DSR scenarios. A report for DECC. Accessed 17th June 2015.

Richardson, I., 2010. Integrated High-resolution Modelling of Domestic Electricity Demand and Low Voltage Electricity Distribution Networks (PhD Thesis). Loughborough University.

Richardson, I., Thomson, M., Infield, D., \& Clifford, C. (2010). Domestic electricity use: A high-resolution energy demand model. Energy and Buildings, 42, 1878-1887. doi:10.1016/j. enbuild.2010.05.023.

Shove, E., Chappells, H., Lutzenhiser, L., Hackett, B., 2008. Comfort in a lower carbon society.

Siano, P. (2014). Demand response and smart grids - A survey. Renewable and Sustainable Energy Reviews, 30, 461-478. doi:10.1016/j.rser.2013.10.022.

Skjølsvold, T. M., \& Ryghaug, M. (2015). Embedding smart energy technology in built environments: A comparative study of four smart grid demonstration projects. Indoor and Built Environment, 24, 878-890.

Sovacool, B. K. (2011). Conceptualizing urban household energy use: Climbing the "energy services ladder.". Energy Policy, 39, 1659-1668.

Stromback, J., Dromacque, C., Yassin, M.H., VaasaETT, G.E.T.T., 2011. The potential of smart meter enabled programs to increase energy and systems efficiency: a mass pilot comparison Short name: Empower Demand. Vaasa ETT.

Torriti, J. (2014). A review of time use models of residential electricity demand. Renewable and Sustainable Energy Reviews, 37, 265-272. doi:10.1016/j. rser.2014.05.034.

Torriti, J., Hassan, M. G., \& Leach, M. (2010). Demand response experience in Europe: Policies, programmes and implementation. Energy, 35, 1575-1583. doi:10.1016/j. energy.2009.05.021.

Walker, G. (2014). The dynamics of energy demand: Change, rhythm and synchronicity. Energy Res. Soc. Sci., 1, 49-55. 
Widén, J., \& Wäckelgård, E. (2010). A high-resolution stochastic model of domestic activity patterns and electricity demand. Applied Energy, 87, 1880-1892. doi:10.1016/j. apenergy.2009.11.006.

Wilke, U., Haldi, F., Scartezzini, J.-L., \& Robinson, D. (2013). A bottom-up stochastic model to predict building occupants' time-dependent activities. Building and Environment, 60, 254 264. doi:10.1016/j.buildenv.2012.10.021
Wilson, C., Hargreaves, T., \& Hauxwell-Baldwin, R. (2015). Smart homes and their users: A systematic analysis and key challenges. Pers. Ubiquitous Comput., 19, 463-476.

Zimmerman, J., Evans, M., Griggs, J., King, N., Harding, L., Roberts, P., Evans, C., 2012. Household Electricity Survey: A study of domestic electrical product usage. Accessed 29th September 2013. 